\title{
Endoftalmite por Candida albicans
}

\author{
Candida albicans endophthalmitis
}

\section{Pedro Duraes Serracarbassa ${ }^{1}$ Patrícia Dotto ${ }^{2}$}

${ }^{1}$ Doutor em Medicina pela Faculdade de Medicina da Universidade de São Paulo; Médico colaborador do Departamento de Oftalmologia, setor de retina e vítreo, do Hospital das Clínicas da Faculdade de Medicina da Universidade de São Paulo.

${ }^{2}$ Médica estagiária de complementação especializada em Retina e Vítreo da clínica oftalmológica do Hospital das Clínicas da Faculdade de Medicina da Universidade de São Paulo.

Endereço para correspondência: Pedro D. Serracarbassa Av. Brigadeiro Faria Lima 1903, cj. 43, São Paulo (SP) CEP 01472-001 -E-mail: serracar@brfree.com.br

\section{RESUMO}

O autor descreve os aspectos epidemiológicos, histopatológicos e clínicos da endoftalmite endógena por Candida albicans. Apresenta ainda novos métodos diagnósticos e opções terapêuticas utilizadas no tratamento das infecções fúngicas intra-oculares, por meio de revisão bibliográfica.

Descritores: Endoftalmite; Candida albicans; Infecções oculares fúngicas

\section{INTRODUÇÃOO}

Os fungos são os agentes mais comuns na endoftalmite endógena, representados na sua maioria pelas espécies de Candida.

Infecções por Candida têm sido observadas desde os tempos de Hipócrates, que descreveu a doença em pacientes debilitados.

A endoftalmite resultante da infecção sistêmica por Candida foi inicialmente descrita em um olho enucleado em $1943^{(1)}$. Em 1958, foi relatado o primeiro caso clinicamente reconhecido como endoftalmite endógena por Candida, confirmado posteriormente por necropsia ${ }^{(2)}$.

Até a metade do século vinte, poucos casos de endoftalmite fúngica endógena foram relatados, porém, na década de sessenta, um grande número de trabalhos foi publicado a respeito, fato este que coincidiu com a introdução dos antibióticos de largo espectro ${ }^{(3)}$. Os fatores que contribuíram para o aumento da incidência de endoftalmite fúngica endógena nas últimas décadas incluem a difusão da antibioticoterapia, hiperalimentação intravenosa, terapia imunossupressiva, além do aumento da sobrevida dos pacientes imunocomprometidos, inclusive aqueles portadores da síndrome da imunodeficiência adquirida (AIDS) ${ }^{(4)}$. Após 1975, foram estudados um total de 167 casos descritos em 52 diferentes publicações ${ }^{(3)}$. Aproximadamente um terço dos casos teve envolvimento bilateral. As condições predisponentes foram similares àquelas relatadas antes de 1975, porém, associações com usuários de drogas ilícitas, prematuridade e AIDS são mais comumente encontradas nos relatos atuais ${ }^{(5)}$. As características dos achados oculares combinados com os achados clínicos e cultura positiva para Candida extra-ocular foram consideradas diagnósticas na maioria dos casos. Pelas descrições, as espécies de Candida, principalmente a C. albicans, foram as principais responsáveis por estas infecções fúngicas.

A C. albicans é um habitante normal do trato gastrointestinal e regiões mucocutâneas, incluindo boca e vagina. Por ser um organismo que habita normalmente o corpo humano, culturas de sangue positivas são freqüentemente atribuídas à contaminação, o que pode levar a um atraso no diagnóstico de uma infecção por Candida.

Imunossupressão, debilidade orgânica, entre outros fatores, podem tornar o fungo patogênico, resultando em uma grave infecção sistêmica ${ }^{(6)}$.

O uso de drogas endovenosas ilícitas é a causa mais comum de endof- 
talmite fúngica endógena. Os pacientes são tipicamente jovens saudáveis, a não ser pela história de uso abusivo de drogas endovenosas ilícitas, dado este que dificulta o diagnóstico preciso ${ }^{(7)}$.

Acredita-se que a origem da infecção fúngica, nestes casos, seja o suco de limão usado para diluição da diacetil-morfina (heroína). As culturas destas drogas isoladas foram negativas para Candida e trabalhos relatam ainda que a heroína teria um efeito fungicida ${ }^{(8)}$.

Usuários de heroína podem desenvolver uma síndrome distinta de candidíase, que se apresenta como: nódulos cutâneos, osteomielite, osteocondrite e endoftalmite. Os sintomas oculares são evidentes dez dias após o uso da injeção intravenosa de heroína. As culturas de Candida mostram-se positivas nas amostras de pele e cartilagem costal, porém são negativas no sangue e urina ${ }^{(9)}$. Diferentes tipos de ácido desoxirribonucléico (DNA) de cepas de C. albicans podem ser encontrados nas epidemias de endoftalmite fúngica em usuários de diacetil-morfina ${ }^{(10)}$.

Os antibióticos intravenosos têm sido associados a infecções por Candida desde $1945^{(11)}$. As bactérias que normalmente habitam a flora intestinal, inibem o crescimento da população de fungos. Alterando-se a flora bacteriana intestinal com o uso de antibióticos sistêmicos, os fungos têm a possibilidade de crescer e invadir tecidos profundos, vasos sangüíneos e linfáticos, resultando em uma doença disseminada, principalmente nos indivíduos imunocomprometidos. Associações com cirurgias gastro-intestinais e uso de antibioticoterapia sistêmica são fatores de risco para o aparecimento da endoftalmite fúngica endógena ${ }^{(12)}$.

A relação entre cateteres intravenosos e candidemia tem sido abordada por diversos autores ${ }^{(13-15)}$. Nestas situações, os pacientes estão geralmente em regime de hiperalimentação e mantidos com cateteres intravenosos por longos períodos como informa, por exemplo, o estudo no qual 133 pacientes faleceram com fungemia documentada, sendo que $32(24 \%)$ destes pacientes estiveram em regime de hiperalimentação antes do óbito ${ }^{(16)}$. Outros autores descreveram que $100 \%$ dos pacientes com fungemia tinham cateteres intravenosos ${ }^{(17)}$.

A imunossupressão, causada por doença sistêmica ou induzida por terapia imunossupressiva, é outro fator associado a infecções sistêmicas por Candida ${ }^{(18-20)}$. Na maioria dos casos, estes pacientes imunossuprimidos receberam antibióticos de largo espectro e tiveram cateteres intravenosos, aumentando assim, o risco desta infecção. Estudos de fungemia adquirida em hospital mostraram que 11 (14\%) de 77 pacientes com fungemia eram portadores de doenças malignas e três casos $(3,8 \%)$ foram submetidos a transplante de órgãos ${ }^{(17)}$. Outro estudo demonstrou que cerca de um terço dos pacientes possuía doenças malignas e $58 \%$ receberam quimioterapia ${ }^{(16)}$.

A AIDS é fator de risco para o desenvolvimento de candidíase $^{(5,21)}$. Apesar da candidíase mucocutânea ser muito comum nos pacientes portadores de AIDS, a candidíase disseminada é infreqüente. Este fato pode ser explicado por ser a infecção sistêmica por Candida comum em indivíduos com neutropenia, enquanto a candidíase mucocutânea ocorre nas alterações da imunidade mediada por células. Por esta razão, a endoftalmite por Candida em pacientes com AIDS, sem história de uso de drogas ilícitas, é rara. Um caso de endoftalmite endógena por Candida foi relatado em um paciente com defeito específico de imunidade celular para este fungo ${ }^{(22)}$.

O papel dos corticosteróides como fator predisponente de candidíase é incerto devido ao fato destes pacientes freqüentemente terem outros fatores associados. A hidrocortisona parece não interferir na atividade fungicida dos neutrófilos ${ }^{(23)}$.

Com relação às manifestações clínicas e à epidemiologia das infecções fúngicas disseminadas em prematuros de muito baixo peso, estes podem apresentar-se com: temperatura corporal instável, hiperglicemia, dificuldade respiratória, distensão abdominal e hipotensão ${ }^{(24-25)}$. Freqüentemente, estas crianças são tratadas com nutrição parenteral, uso de cateteres e antibióticos de largo espectro. As culturas são negativas na maioria destes prematuros e o diagnóstico é usualmente baseado no aspecto fundoscópico.

Outros fatores predisponentes menos comuns de candidíase sistêmica e endoftalmite endógena por Candida são: puerpério $^{(26)}$, insuficiência hepática ${ }^{(3)}$, alcoolismo ${ }^{(15)}$, manipulação genito-urinária ${ }^{(27)}$, procedimentos neurocirúrgicos ${ }^{(28)}$, megacólon tóxico ${ }^{(29)}$, aborto induzido ${ }^{(30)}$, neutropenia ${ }^{(31)}$, transplante de medula óssea ${ }^{(32-33)}$ e idiopática ${ }^{(34)}$.

Vários estudos exploraram a relação de candidemia e endoftalmite. Autores relataram que $30 \%$ dos pacientes com candidemia tinham evidências clínicas ou após o óbito de endoftalmite por Candida ${ }^{(35)}$. Foram analisados, em estudo retrospectivo, 77 pacientes com fungemia e observou-se que $11(14,2 \%)$ apresentavam sinais de endoftalmite ${ }^{(17)}$.

Trabalho prospectivo em 27 pacientes com fungemia por $C$. albicans apresentou endoftalmite em $37 \%$ dos casos (10 pacientes) $^{(36)}$. Apenas $1(9 \%)$ em 11 pacientes com fungemia por Candida de outra espécie desenvolveu endoftalmite, o que confirma outros relatos anteriores da alta patogenicidade da $C$. albicans quando comparada a outras espécies ${ }^{(37)}$.

\section{ACHADOS CLÍNICOS}

A endoftalmite fúngica apresenta-se na grande maioria dos casos como uma infecção de caráter indolente. Os sintomas mais comumente encontrados na infecção intra-ocular por Candida são: embaçamento visual, dor e fotofobia. A dor mostra-se menos intensa quando comparada à forma bacteriana, fato este que dificulta o seu diagnóstico. Os pacientes podem ainda apresentar queixa de pontos flutuantes no campo de visão. Indivíduos extremamente debilitados podem não apresentar sintomas. O envolvimento bilateral ocorre em cerca de um quarto dos casos de endoftalmite endógena e é caracterizado pela similar gravidade, embora possa ocorrer intervalo de dias entre o aparecimento dos sinais em ambos os olhos. O 
sinal oftalmológico mais característico de endoftalmite por Candida é a lesão branca, pouco delimitada, envolvendo a coróide e retina, localizada no pólo posterior. A lesão pode ser única ou múltipla e apresentar um aspecto estrelado semelhante àquele observado nas infecções fúngicas corneanas. Hemorragias intra-retinianas podem circundar a lesão branca, levando ao aspecto das "manchas de Roth". As opacidades vítreas são tipicamente branco-amareladas e conectadas por traves, produzindo uma imagem semelhante a um "colar de pérolas". A origem destas opacidades foi primeiramente descrita em1964 ${ }^{(38)}$ e posteriormente em $1980^{(39)}$, como uma gradual elevação da lesão retiniana que finalmente se rompia e migrava em direção ao vítreo. Outros sinais comuns, mas menos característicos, são: injeção conjuntival e ciliar, precipitados ceráticos, células inflamatórias na câmara anterior, com ou sem hipópio. Episclerite, esclerite, membrana pupilar, membrana ciclítica, edema do nervo óptico e perivasculite são também descritos. Alterações do segmento posterior como: membrana epirretiniana, tração vitreorretiniana e descolamento de retina podem ocorrer nas fases tardias da doençca ${ }^{(40)}$.

Após a fase aguda da infecção, as lesões da retina e coróide evoluem com cicatrizes fibrosas, tendo sido descrita a ocorrência de membranas neovasculares de coróide no local da cicatriz ${ }^{(41)}$. Nos olhos com intensa inflamação vítrea, as típicas lesões coriorretinianas podem ser obscurecidas pela opacidade vítrea. Estes casos ocorrem com mais freqüência nos pacientes usuários de drogas ilícitas pelo fato destes procurarem auxílio médico nas fases tardias da infecção.

\section{HISTOPATOLOGIA}

A histopatologia da endoftalmite por Candida foi descrita inicialmente em um caso diagnosticado por necrópsia ${ }^{(1)}$. Edwards et al. (1974) apresentaram um grande número de casos com relatos histopatológicos ${ }^{(19)}$. As típicas lesões coriorretinianas apareciam macroscopicamente como elevações brancas de superfície lisa, algumas vezes circundadas por hemorragia. Microscopicamente, as lesões eram compostas por uma inflamação supurativa envolvendo a coróide e estendendo-se para a retina. Os organismos estavam tipicamente concentrados próximos ao lado interno da retina destruída. Descolamentos serosos da retina foram observados. Mais da metade dos casos relatados tinham papilite associada.

Apesar dos fungos não terem sido encontrados na coróide e retina, eles foram relatados dentro de nódulos vítreos circundados por leucócitos polimorfos nucleares. Ocasionalmente, linfócitos e células plasmáticas foram encontrados, porém sem evidências de inflamação granulomatosa.

O envolvimento do segmento anterior é um achado incomum no exame histopatológico, porém pode haver comprometimento do corpo ciliar, conjuntiva e esclera ${ }^{(42)}$. Os autores demonstraram um denso infiltrado mononuclear do limbo, íris, corpo ciliar e coróide, com elevação da retina perivascular e necrose retiniana.

\section{MÉTODOS DIAGNÓSTICOS}

A endoftalmite por Candida deve ser suspeitada em todos os pacientes com os fatores predisponentes já supracitados que apresentem coriorretinite ou uveíte posterior progressiva. A presença das típicas lesões coriorretinianas brancas ou das opacidades vítreas em "colar de pérolas" é altamente sugestiva.

O diagnóstico presuntivo de endoftalmite endógena deve ser feito se as culturas de Candida em outros locais apresentarem-se positivas na presença de um quadro ocular característico. A Candida pode ser obtida através da cultura de urina, sangue, ou outros locais como cateteres endovenosos, semanas antes do aparecimento dos sintomas oculares ${ }^{(43)}$. Na ausência de culturas positivas de Candida de locais extra-oculares ou sinais oculares inespecíficos com envolvimento vítreo, opta-se pela biópsia e cultura do humor vítreo para confirmação diagnóstica. $\mathrm{O}$ reconhecimento da causa do processo inflamatório intra-ocular, estéril ou infeccioso, e a determinação do agente etiológico através de estudos de sensibilidade são fundamentais no tratamento da endoftalmite. $\mathrm{O}$ vítreo é o principal sítio intra-ocular de alojamento dos organismos. A presença do cristalino, cápsula posterior ou lente intra-ocular não previne a invasão da cavidade vítrea pelos microrganismos. Autores demonstraram experimentalmente que o segmento anterior possui uma maior resistência aos agentes invasores em relação ao segmento posterior ${ }^{(44)}$. Os autores inocularam uma grande quantidade de organismos na câmara anterior de coelhos e não foram capazes de induzir um quadro de endoftalmite progressiva. $\mathrm{O}$ inverso ocorreu quando uma pequena quantidade de germes foi introduzida na câmara posterior e produziu infecção intra-ocular. Usando modelos animais, estudos confirmaram o diagnóstico em $62 \%$ dos olhos com aspiração do humor vítreo e relataram a aspiração do humor aquoso como sendo de pouco valor diagnóstico ${ }^{(45)}$. Apesar do baixo grau de positividade das culturas obtidas do humor aquoso, a possibilidade, ainda que remota, dos organismos serem encontrados na câmara anterior torna a obtenção deste material recomendável.

A coleta das amostras do humor vítreo pode ser realizada através da punção via pars plana com agulha fina ou com o auxílio do vitreófago ${ }^{(46)}$. Nos casos suspeitos de etiologia fúngica, recomenda-se a vitrectomia diagnóstica no intuito de colher a maior concentração possível de fungos, pois os mesmos situam-se seqüestrados na cavidade vítrea, diferentemente das colônias de bactérias que se apresentam de forma difusa no corpo vítreo. A amostra do vítreo, se diluída nos líquidos de infusão da vitrectomia, deve ser filtrada por centrifugação ou com filtros de papel (milipore). O material obtido da câmara anterior e posterior deve ser imediatamente inoculado nos meios de cultura apropriados e colocado em lâminas para coloração e observação microscópica ${ }^{(47)}$.

A Candida é uma levedura que se apresenta na forma de micélio e hifa, porém mantém a morfologia de hifa na maioria das vezes, exibindo a característica de pseudomicélio em certos ambientes nutricionais. 
Os métodos clássicos para detecção e identificação de leveduras do gênero Candida e da espécie Candida albicans são divididos em métodos para visualização e recuperação fúngica e testes para identificação de leveduras. A visualização do fungo é possível através do uso de técnicas de coloração específicas, nas quais a levedura pode ser identificada por observação microscópica direta. Dentre os corantes usados destacam-se: Gram, Giemsa, prata Gomori, hidróxido de potássio, branco calcoflúor, entre outros. Estes fungos crescem rapidamente em quase todos os meios de cultura, mas o ágar Sabouraud com ciclohexamida em temperatura ambiente e o meio BHI (brain heart infusion) a 36 graus são os mais recomendados quando o organismo é clinicamente suspeito. $\mathrm{Na}$ ausência dos meios apropriados, o material pode ser diretamente inoculado em frascos com ágar sangue. Colônias esbranquiçadas aparecem em 24 a 48 horas após a inoculação ${ }^{(43)}$.

São testes para identificação de leveduras: prova de assimilação de fontes de carbono e nitrogênio, provas de fermentação, teste de tubo germinativo, resistência à ciclohexamida, testes de termotolerância, estudo morfológico em ágar fubá com Tween 80, hidrólise da uréia e produção de fenoloxidase. Estes testes resultam num perfil bioquímico-nutricional específico, permitindo a diferenciação entre as espécies de leveduras, especialmente as do gênero Candida. Nenhuma das provas de identificação de fungos apresenta sensibilidade e especificidade de $100 \%$; portanto, os métodos tradicionais de visualização e recuperação são recomendados em qualquer laboratório que pretenda identificar espécies de leveduras ${ }^{(48)}$.

A ultra-sonografia ocular é útil na detecção de envolvimento do segmento posterior e na monitorização da evolução do processo infeccioso. São descritos ecos de baixa refletividade e alta mobilidade no vítreo, grandes vacúolos intravítreos e espessamento da hialóide posterior na maioria dos casos. No estudo ultra-sonográfico ${ }^{(49)}$, o descolamento de coróide foi determinado como fator de mau prognóstico visual nos pacientes portadores de endoftalmite.

Novos métodos diagnósticos têm sido testados nos últimos anos para a detecção precoce das infecções fúngicas. Dentre eles, citamos: uso de marcadores moleculares para identificação de fungos nos tecidos humanos ${ }^{(50)}$, a reação da cadeia de polimerase ${ }^{(10)}$, dosagens séricas e vítreas de Darabinitol, beta-D-glucan e do antígeno de C. albicans $^{(51)}$, uso de anticorpos monoclonais radioiodinizados ${ }^{(52)}$ e dosagem de anticorpos IgG no humor aquoso ${ }^{(53)}$. Os novos métodos descritos acima abrem novas perspectivas diagnósticas, porém necessitam de maiores estudos.

\section{TRATAMENTO}

Apesar do desenvolvimento de novos agentes antifúngicos, das vias alternativas de administração e dos avanços na cirurgia vitreorretiniana, o tratamento da endoftalmite fúngica ainda se constitui num desafio para a oftalmologia.

A anfotericina B é o antifúngico de eleição no tratamento da endoftalmite por Candida. Ela foi descoberta em $1956^{(54)} \mathrm{e}$ utilizada no tratamento da candidíase e endoftalmite em $1960^{(55)}$. É um dos vários antibióticos polienos e, devido às suas duplas ligações, é chamada de heptaeno polieno.

O composto atua ligando-se aos esteróis da membrana celular, resultando num extravasamento dos constituintes celulares e morte celular ${ }^{(56)}$. É uma substância fungistática e fungicida isolada de cepas de Streptomyces nodosus. Seu espectro de ação inclui todas as espécies de Candida, algumas espécies de Aspergillus, Blastomyces dermatitidis, entre outros fungos. A droga não é absorvida pelo trato gastrointestinal e deve ser administrada por via intravenosa. O tratamento sistêmico, em doses de $0,25 \mathrm{mg} / \mathrm{kg}$ a $1,5 \mathrm{mg} / \mathrm{kg}$ ao dia, é geralmente indicado nos casos de candidíase associada à coriorretinite sem opacidades vítreas ${ }^{(57)}$.

A vitrectomia via pars plana e a injeção intravítrea de 5 a 10mg de anfotericina B são as opções terapêuticas nos casos de opacidades vítreas moderadas ou graves ${ }^{(58)}$. Existindo a associação com candidemia, o uso da anfotericina B intravenosa está indicado. Nos casos de opacidades vítreas leves, sem associação com candidemia, considera-se somente o tratamento com injeções intravítreas da droga ${ }^{(59)}$.

Mesmo sendo a anfotericina $\mathrm{B}$, atualmente, o antifúngico mais eficaz disponível, seu uso é restrito pela sua toxicidade sistêmica e local. A disfunção renal é o mais importante efeito tóxico e ocorre na grande maioria dos pacientes. É usualmente reversível quando cessada a terapia, porém reduções permanentes na filtração glomerular podem permanecer. Os valores do hematócrito, potássio sérico, uréia nitrogenada do sangue, creatinina e dióxido de carbono, bem como análises da urina, devem ser obtidos quinzenalmente. Efeitos colaterais, como: distúrbios gastro-intestinais, febre, calafrios, tromboflebite, hepatotoxicidade, neurotoxicidade, reações alérgicas e parada cardíaca, podem ocorrer durante a infusão rápida da droga ${ }^{(60)}$.

Apesar da anfotericina B ser usualmente eficaz, infecções intra-oculares persistentes têm sido relatadas nos casos de envolvimento vítreo ${ }^{(35,42)}$. Especula-se que níveis subterapêuticos intravítreos, alcançados quando a droga é administrada por via endovenosa, sejam os responsáveis pelo fracasso terapêutico nos casos descritos. Foi demonstrada, em trabalho experimental, a presença de fungos na retina, coróide e vítreo de coelhos inoculados com cepas de Candida e tratados vinte e oito dias com anfotericina B endovenosa ${ }^{(61)}$. Observou-se histologicamente a presença de organismos viáveis em um paciente portador de endoftalmite fúngica tratado com repetidas doses de anfotericina $\mathrm{B}$ endovenosa ${ }^{(62)}$. Injeções intravítreas de 5 a $10 \mathrm{mg}$ podem eventualmente causar necrose retiniana se administradas próximas à retina ou injetadas de forma rápida ${ }^{(63)}$.

A natamicina (pimaricina) pertence à mesma classe e apresenta o mesmo espectro de ação da anfotericina B. Infelizmente, sua capacidade de penetrar no vítreo é pequena e estudos demonstraram ser uma droga altamente tóxica quando injetada no vítreo ${ }^{(64-65)}$.

A nistatina é um fungistático e fungicida isolado de cepas de Streptomyces noursei. Seu espectro de ação e mecanismo 
são semelhantes aos da anfotericina B, porém é altamente tóxica quando usada por via sistêmica ou intravítrea ${ }^{(66)}$.

A fluorocitosina foi descoberta em 1957 e usada no tratamento da candidemia em 1968. A vantagem da fluorocitosina sobre a anfotericina B é a sua excelente absorção gastrointestinal. Os efeitos colaterais mais comuns são a diarréia, náusea e vômitos. São relatados também trombocitopenia, anemia e leucopenia. A penetração vítrea da fluorocitosina após a administração oral é satisfatória ${ }^{(67-68)}$. Entretanto, seu maior problema é a alta porcentagem de resistência das cepas de Candida. Entre 7 e $47 \%$ das cepas de Candida isoladas antes do tratamento eram resistentes à droga e a sua resistência geralmente ocorre durante o tratamento ${ }^{(69)}$. Em estudo experimental, autores relataram que a fluorocitosina, droga que apresenta alta porcentagem de resistência a C. albicans, poderia ser administrada nas doses de até $100 \mathrm{mg}$, sem efeitos tóxicos para a retina $^{(70)}$.

Nos últimos anos, novas séries de compostos imidazoles têm sido estudados.

Os imidazoles são menos tóxicos que os antibióticos polienos e eficazes contra várias espécies de fungos. O clotrimazol foi o primeiro imidazole estudado, porém sua capacidade de induzir enzimas microssomais do fígado limitou seu uso

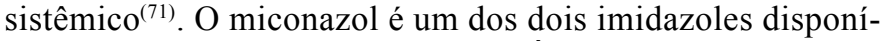
veis para administração sistêmica. É pouco absorvido pelo trato gastrointestinal e deve ser administrado por via intravenosa. A dosagem recomendada para o tratamento das espécies de Candida é de 600 a $3600 \mathrm{mg} / \mathrm{kg}$ ao dia $^{(72)}$. Este antifúngico apresenta uma concentração inibitória mínima in vitro relativamente alta para a maioria das espécies de Candida, além de apresentar baixa penetração vítrea quando administrado por via intravenosa ${ }^{(73)}$. Estes dados explicariam o seu fracasso no tratamento da endoftalmite endógena por Candida encontrado na literatura ${ }^{(74)}$.

Os efeitos colaterais mais comuns são: tromboflebite, arritmia, anafilaxia, parada respiratória, febre, calafrios, entre outros. Devido a sua limitada ação antifúngica contra Candida e a sua baixa penetração vítrea, sua indicação é restrita a casos de cepas resistentes ao tratamento com anfotericina B. Autores demonstraram que injeções intravítreas de 40mg de miconazol não apresentaram evidências de toxicidade para a retina de coelhos albinos ${ }^{(75)}$.

O cetoconazol é um imidazole aprovado como antifúngico sistêmico em 1981. Atua inibindo os esteróis da membrana celular, porém difere do miconazol por ser bem absorvido pelo trato gastrointestinal ${ }^{(76)}$. A dose de 200 a $800 \mathrm{mg} / \mathrm{kg}$ ao dia é variável de acordo com o tipo de infecção que se pretende $\operatorname{tratar}^{(77)}$. Apresenta uma baixa porcentagem de efeitos tóxicos graves. São relatados náuseas, vômitos e diarréia. Foram reportados casos de disfunção hepática variando de elevação assintomática das enzimas até necrose hepática fatal ${ }^{(78)}$. O cetoconazol possui uma excelente ação in vitro e in vivo contra a maioria das espécies de Candida. Entretanto, sua penetração intravítrea e eficácia no tratamento da endoftalmite por Cândida são motivos de controvérsia na literatura.
Acredita-se que, para o tratamento ser eficaz, o antifúngico deva ser administrado por longos períodos ${ }^{(79)}$. O cetoconazol está indicado nos casos de coriorretinite presumida por Candida sem associação com candidemia ou nos pacientes severamente debilitados que não podem receber a anfotericina $\mathrm{B}$ intravenosa. $\mathrm{O}$ cetoconazol não produziu alterações tóxicas na retina de coelhos nas dosagens intravítreas de até $550 \mathrm{mg}{ }^{(80)}$, assim como seu análogo, o oxiconazol, nas doses de $100 \mathrm{mg}^{(81)}$.

Os triazoles são novos derivados azoles que, além de possuir as mesmas propriedades dos imidazoles, lesam os fosfolipídios da membrana celular, o que confere a eles novas propriedades antifúngicas. O itraconazol é ativo contra uma variedade de fungos, entre eles, as espécies de Candida. É bem absorvido por via oral em doses de 50 a $400 \mathrm{mg}$ ao dia. Apresenta baixa toxicidade, com relatos de náusea e aumento transitório de enzimas hepáticas ${ }^{(82)}$. O fluconazol apresenta alta eficácia contra espécies de Candida e vários outros fungos. Pode ser administrado por via oral na dosagem de 200 a $400 \mathrm{mg}$ ao dia ou, menos freqüentemente, por via intravenosa e apresenta a melhor farmacocinética entre todos os antifúngicos estudados $^{(83)}$. Sua toxicidade é semelhante à do itraconazol, porém sua atividade in vivo ainda permanece controversa devido à baixa penetração na cavidade vítrea dos compostos imidazoles $^{(84)}$.

O uso de fluconazol intravítreo na dosagem de $100 \mathrm{mg}^{(85)} \mathrm{e}$ itraconazol $10 \mathrm{mg}^{(86)}$ não produziu efeitos tóxicos retinianos em modelos experimentais.

\section{NOVAS OPCÕES TERAPÊUTICAS}

Baseando-se nos dados relativos às limitações dos diversos antifúngicos disponíveis e nos princípios da terapia intravítrea, desenvolveram-se estudos de novos antifúngicos.

$\mathrm{O}$ cilofungin, de alta eficácia in vitro contra $C$. albicans, apresentou-se não tóxico para a retina ${ }^{(87)}$, assim como o faerifungin, um novo agente antifúngico de atividade restrita contra $C$. albicans, não apresentou alterações no ERG e na microscopia óptica e eletrônica nas doses intravítreas de até $100 \mathrm{mg}^{(88)}$.

Dentre os mais recentes antifúngicos estudados, destacase a espartanamicina $B$, que se mostrou segura e eficaz na dosagem intravítrea de $10 \mathrm{mg}$ em modelos experimentais de endoftalmite por Candida albicans ${ }^{(89-90)}$.

Autores descreveram o uso de injeções intravítreas de dexametasona associada à anfotericina $\mathrm{B}$ no tratamento da endoftalmite experimentalmente induzida por C. albicans ${ }^{(91)}$. Os autores compararam o tratamento com injeções intravítreas de apenas anfotericina B e observaram que os coelhos tratados com corticosteróides, além da cura do processo infeccioso, evoluíram com o desaparecimento das opacidades vítreas iniciais. Os coelhos tratados somente com anfotericina B obtiveram a cura da endoftalmite, porém, permaneceram com opacidades vítreas residuais. Estudos posteriores também apresentaram resultados satisfatórios com a associação de corticosteróides e antifúngicos ${ }^{(92-93)}$. 
Apesar da grande variedade de antifúngicos disponíveis, nota-se que a maioria destes compostos apresentam problemas relacionados à toxicidade sistêmica e ocular, farmacocinética, penetração vítrea e eficácia. Estudos futuros são necessários objetivando encontrar novas formas de tratamento para endoftalmite por C. albicans.

\section{ABSTRACT}

The author describes epidemiological, histopathological and clinical aspects of endogenous Candida albicans endophthalmitis. He also presents new diagnostic methods and therapeutical options to treat intraocular fungal infections, based on literature review.

Keywords: Endophthalmitis; Candida albicans; Eye infections, fungal

\section{REFERÊNCIAS}

1. Miale JB. Candida Albicans infection confused with tuberculosis. Arch Pathol 1943;35:427-31.

2. Van Buren JM. Septic retinitis due to Candida albicans. Arch. Pathol. 1958;65:137

3. Brod RD, Clarkson JG, Flynn Jr. HW, Green WR. Endogenous fungal endophthalmitis. In: Duane TD, Jaeger EA, editors. Clinical Ophthalmology. Philadelphia: Lippincott; 1990.

4. Clift RA. Candidiasis in the transplant patient. Am J Med 1984;77(Suppl 4D):34-8.

5. Heinemann MH, Bloom AF, Horowitz J. Candida albicans endophthalmitis in a patient with AIDS: Case report. Arch Ophthalmol 1987;105:1172-3.

6. Deutsch D, Adler S, Teller J, Savir H. Endogenous candidal endophthalmitis. Ann Ophthalmol 1989;21:260-5.

7. Getnick RA, Rodrigues MM. Endogenous fungal endophthalmitis in a drug addict. Am J Ophthalmol 1974;77:680-3.

8. Shankland GS, Richardson MD, Dutton GN. Source of infection in Candida endophthalmitis in drug addicts. Br Med J (Clin Res Ed) 1986;292:1106-7.

9. Collignon PJ, Sorrell TC. Disseminated candidiasis: evidence of a distinctive syndrome in heroin abusers. Br Med J (Clin Res Ed) 1983;287:861-2.

10. Clemons KV, Shankland GS, Richardson MD, Stevens DA. Epidemiologic study by DNA typing of a Candida albicans outbreak in heroin addicts. J Clin Microbiol 1991;29:205-7.

11. Seelig MS. The role of antibiotics in the pathogenesis of Candida infections. Am J Med 1966;40:887-917.

12. Neves RA, Rigueiro MP, Bordon AF, Burnier JR. Endoftalmite micótica endógena: aspectos clínicos e histopatológicos de 3 casos. Arq Bras Oftalmol 1990;53:20-1.

13. Dellon AL, Stark WJ, Chretien PB. Spontaneous resolution of endogenous Candida endophthalmitis complicating intravenous hyperalimentation. Am J Ophthalmol 1975;79:648-54.

14. Rose HD. Venous catheter-associated candidemia. Am J Med Sci 1978;275: 265

15. Henderson DK, Edwards JEJR, Montgomerie JZ. Hematogenous Candida endophthalmitis in patients receiving parenteral hyperalimentation fluids. J Infect Dis 1981;143:655-61.

16. McDonnell, McDonnell JM, Brown RH, Green WR. Ocular involvement in patients with fungal infections. Ophthalmology 1985;92:706-9.

17. Klein JJ, Watanakunakorn C. Hospital-acquire fungemia: Its natural course and clinical significance. Am. J. Med. 1979;67:51-8.

18. Bodey GP. Infections in cancer patients. Cancer Treat. Rev. 1975;2:89-128.

19. Edwards Jr JE, Foos RY, Montgomerie JZ, Guze LB. Ocular manifestations of Candida septicemia: Review of seventy-six cases of hematogenous Candida endophthalmitis. Medicine (Baltimore)1974;53:47-75.

20. Wingard JR, Merz WG, Saral R. Candida tropicalis: a major pathogen in immunocompromised patients. Ann Intern Med 1979;91:539-41.
21. Dunn JP, Holland GN. Human immunodeficiency virus and opportunistic ocular infections. Infect Dis Clin North Am 1992;6:909-23.

22. Kirkpatrick $\mathrm{CH}$. Host factors in defense against fungal infections. Am J Med 1984;77 (Suppl 4D):1-12.

23. Young RC, Bennett JE, Geelhoed GW, Levine AS. Fungemia with compromised host resistence. A study of 70 cases. Ann. Intern. Med. 1974;80: 605-12.

24. Annable WL, Kachmer ML, DiMarco M, DeSantis D. Long-term follow-up of Candida endophthalmitis in the premature infant. J Pediatr Ophthalmol Strabismus 1990;27:103-6.

25. Enzenauer RW, Calderwood S, Levin AV, Elder JE, Morin JD. Screening for fungal endophthalmitis in children at risk. Pediatrics 1992;90:451-7.

26. Cantrill HL, Rodman WP, Ramsay RC, Knobloch WH. Postpartum Candida endophthalmitis. JAMA 1980;243:1163-5.

27. Sixbey JW, Caplan ES. Candida parapsilosis endophthalmitis. Ann Intern Med 1978;89:1010-1.

28. Cushman AR, Friedman G, Capsavage J. Systemic candidiasis and endophthalmitis in neurosurgical patients. Report of three cases. J Neurosurg 1976;45:95-7.

29. Henderson T, Irfan S. Bilateral endogenous Candida endophthalmitis and chorioretinitis following toxic megacolon. Eye 1996;10(Pt 6):755-7.

30. Chen SJ, Chung YM, Liu JH. Endogenous Candida endophthalmitis after induced abortion. Am J Ophthalmol 1998;125:873-5.

31. Swerdloff JN, Filler SG, Edwards Jr JE. Severe candidal infections in neutropenic patients. Clin Infect Dis 1993;17(Supp.2):S457-67.

32. Griffin JR, Pettit TH, Fishman LS, Foos RY. Blood-borne Candida endophthalmitis: a clinical and pathological study of 21 cases. Arch Ophthalmol 1973;89:450-6.

33. Coskuncan NM, Jabs DA, Dunn JP, Haller JA, Green WR, Vogelsang GB, et al. The eye in bone marrow transplantation. VI. Retinal complications. Arch Ophthalmol 1994;112:372-9.

34. Kostick DA, Foster RE, Lowder CY, Meyers SM, McHenry MC. Endogenous endophthalmitis caused by Candida albicans in a healthy woman. Am J Ophthalmol 1992;113:593-5.

35. Griffin JR, Foos RY, Pettit TH. Relationship between Candida endophthalmitis, candidemia, and disseminated candidiasis. In: XXII Concilium Ophthalmologicum. Paris 1974. p.661

36. Parke DWII, Jones DB, Gentry LO. Endogenous endophthalmitis among patients with candidemia. Ophthalmology 1982;89:789-96.

37. Fujita NK, Henderson DK, Hokey LJ, Guze LB, Edwards Jr JR. Comparative ocular pathogenicity of Cryptococcus neoformans, Candida glabrata, and Aspergillus fumigatus in the rabbit. Invest Ophthalmol Vis Sci 1982;22:410-4.

38. Viallenfont H, Chaptal J, Rioux J. Mycoses rétiniennes: a propos de trois observations. Bull Mem Soc Fr Ophthalmol 1964;77:387.

39. Palmer EA. Endogenous Candida endophthalmitis in infants. Am J Ophthalmol 1980;89:388-95.

40. McDonald HR, DeBustros S, Sipperley JO. Vitrectomy for epiretinal membrane with Candida chorioretinitis. Ophthalmology 1990;97:466-9.

41. Shah GK, Fischer D, Fineman MS, Sharma S, Maguire J. Subretinal neovascularization secondary to Candida endophthalmitis: long term follow-up after submacular surgery. Retina 1999;19:81-2.

42. Aguilar GL, Blumenkranz MS, Egbert PR, McCulley JP. Candida endophthalmitis after intravenous drug abuse. Arch Ophthalmol 1979;97:96-100.

43. Mames RN, Friedman SM, Stinson WG, Margo CE. Positive vitreous cultures from eyes without signs of infectious endophthalmitis. Ophthalmic Surg Lasers 1997;28:365-9.

44. Maylath FR, Leopold JH. Study of experimental intraocular infection. Am J Ophthalmol 1955;40:86.

45. Henderson DK, Edwards Jr JE, Ishida K, Guze LB. Experimental hematogenous Candida endophthalmitis: diagnosis approaches. Infect Immun 1979;23: 858-62.

46. Peyman GA. A pneumovitrector for the diagnostic biopsy of the vitreous. Ophthalmic Surg Lasers 1996;27:246-7.

47. Joondeph BC, Flynn Jr HW, Miller D, Joondeph HC. A new culture method for infectious endophthalmitis. Arch Ophthalmol 1989;107:1334-7.

48. Kwon-Chung KJ, Bennet JE. Microbiology of fungal infections. In: KwonChung KJ, Bennet JE. Medical Mycology. 2.ed. Philadelphia: Lea \& Febirger; 1992. p. 315-8.

49. Dacey MP, Valencia M, Lee MB, Dugel PU, Ober RR, Green RL, et al. Echographic findings in infections endophthalmitis. Arch Ophthalmol 1994;112:1325-33.

50. Kappe R, Okeke CN, Fauser C, Maiwald M, Sonntag HG. Molecular probes for the detection of pathogenic fungi in the presence of human tissue. J Med Microbiol 1998;47:811-20. 
51. Mathis A, Malecaze F, Bessieres MHJ, Arne JL, Seguela JP, Bec P. Immunological analysis of the aqueous humour in Candida endophthalmitis. II: Clinical study. Br J Ophthalmol 1988;72:313-6.

52. Poulain D, Deveaux M, Cailliez JT, Hossein-Foucher S, Dutoit E, Camus D, et al. Imaging of systemic Candida albicans infections with a radiodinated monoclonal antibody: experimental study in the guinea pig. Int $\mathbf{J}$ Rad Appl Instrum (B) 1991;18:677-86.

53. Bessieres MH, Malecaze F, Lias MD, Recco P, Fleutiaux S, Bec P, et al. Local production of specific antibodies in the aqueous humor in experimental Candida endophthalmitis in rabbits. Ann Biol Clin(Paris) 1988;45:651-6.

54. Gold W, Stout HA, Pagano JF, Donovick R. Amphotericins A and B: Antifungal antibiotics produced by a streptomycete: I. In vitro studies. In: Welch H, Marti-Ibanez F., editors. Antibiotics Annual 1955-1956. New York: Medical Encyclopedia;1956. p.579.

55. Louria DB, Dineen P. Amphotericin B in the treatment of disseminated moniliasis. JAMA 1960;174:273.

56. Medoff G, Kobayashi GS. Strategies in the treatment of systemic fungal infections. N Engl J Med 1980;302:145-55.

57. Essman TF, Flynn Jr HW, Smiddy WE, Brod RD, Murray TG, Davis JL, et al. Treatment outcomes in a 10-year study of endogenous fungal endophthalmitis. Ophthalmic Surg Lasers 1997;28:185-94.

58. Brod RD, Flynn Jr HW, Clarkson JG, Pflugfelder SC, Culberston WW, Miller D. Endogenous Candida endophthalmitis. Management without intravenous amphotericin B. Ophthalmology 1990;97:666-72; discussion p. $672-4$.

59. Peyman GA, Raichand M, Bennett TO. Management of endophthalmitis with pars plana vitrectomy. Br J Ophthalmol 1980;64:472-5.

60. Butler WT. Pharmacology, toxicity and therapeutic usefulness of amphotericin B. JAMA 1966;195:371-5.

61. Jones DB, Green MT, Osato MS, Broberg PH, Gentry LD. Endogenous Candida albicans endophthalmitis in the rabbit: chemotherapy for systemic effect. Arch Ophthalmol 1981;99:2182-7.

62. Kinyoun JL. Treatment of Candida endophthalmitis. Retina 1982;2:215-22.

63. Peyman GA, Schulman JA. Drug therapy for endophthalmitis. In: Peyman GA, Schulman JA. Intravitreal surgery: principles and practice. 2.ed. Norwalk, Connecticut: Appleton-Century-Crofts; 1986. p. 851-912.

64. Ellison AC. Intravitreal effects of pimaricin in experimental fungal endophthalmitis. Am J Ophthalmol 1976;81:157-61.

65. Ellison AC. Intravenous effects of pimaricin on mycotic endophthalmitis. Ann. Ophthalmol 1979;11:157-61.

66. Fine BS, Zimmerman LE. Therapy of experimental intraocular Aspergillus infection. Arch Ophthalmol 1960;64:849-61.

67. Diasio RB, Bennet JE, Myers CE. Mode of action of 5-fluorocytosine. Biochem Pharmacol 1978;27:703-7.

68. Walsh A, Haft DA, Miller MH, Loran MR, Friedman AH. Ocular penetration of 5-fluorocytosine.Invest Ophthalmol Vis Sci 1978;17:691-4.

69. Shadamy S. Further in vitro studies with 5-fluorocytosine. Infect Immun $1970 ; 2 ; 484$

70. Yoshizumi MO, Silverman C. Experimental intravitreal 5-fluorocytosine. Ann Ophthalmol 1985;17:58-61.

71. Driebe WT, Storn GA, Epstein RT, Visvesvara GS, Adim M, Komadina T. Acanthamoeba keratitis: potential role for topical clotrimazole in combination chemotherapy. Arch Ophthalmol 1988;106:1196-201.

72. Kucers A, Bennett NM. Antimyocotics. In: Kucer A, Bennett NM. The use of antibiotics: a comprehensive review with clinical emphasis. $3^{\text {rd }}$.ed. Philadelphia: Lippincott; 1979. p.967-78.

73. Joes DB. Therapy of postsurgical fungal endophthalmitis. Ophthalmology 1978;85:357-73.

74. Dixon D, Shadomy S, Shadomy JH, Espinel-Ingroff A, Kerkering TM. Comparison of the in vitro antifungal activities of miconazole and a new imidazole R 41,400. J Infect Dis1978;138:245-8.

75. Tolentino FI, Foster CS, Lahav M, Liu LH, Rabin AR. Toxicity of intravitreous miconazole. Arch Ophthalmol 1982;100:1504-9.

76. Borgers M, Van Den Bossche H, DeBrabander M. The mechanism of action of the new antimycotic ketoconazole. Am J Med 1983;74(1B):2-8.

77. Lemp MA, Blackman HJ, Koffler BH. Therapy for bacterial and fungal infections. Int Ophthalmol Clin 1980;20:135-7.

78. Janssen PAJ, Symoens JE. Hepatic reactions during ketoconazole treatment. Am J Med 1983;74(1B):80-5.

79. Stern WH, Tamura E, Jacobs RA, Pong VG, Stone RD, O'Day DM, et al. Epidemic post surgical Candida parapsilosis endophthalmitis: clinical findings and management of 15 consecutive cases. Ophthalmology 1985;92:1701-9.

80. Yoshizumi MO, Banihashemi AR. Experimental intravitreal ketoconazole in DMSO. Retina 1988;8:210-5.

81. Schulman JA, Peyman GA, Dietlein J, Fiscella R. Toxicity of intravitreal oxiconazole. Int Ophthalmol. 1989;13:201-3.

82. Saag MS, Dismukes WE. Azole antifungal agents: emphasis on new triazoles. Antimicrob Agents Chemother 1988;32:1-8.

83. Laatikainen L, Tuominen M, Von Dickhoff K. Treatment of endogenous fungal endophthalmitis with systemic fluconazole with or without vitrectomy. Am J Ophthalmol 1992;113:205-7.

84. Borne MJ, Elliott JH, O'Day DM. Ocular fluconazole treatment of Candida parapsilosis endophthalmitis after failed intravitreous amphotericin B. Arch Ophthalmol 1993;111:1326-7.

85. Schulman JA, Peyman GA, Fiscella R, Small G, Coats M, Wajszczuk C P, et al. Toxicity of intravitreal injection of fluconazole in the rabbit. Can $\mathrm{J}$ Ophthalmol 1987;22:304-6.

86. Schulman JA, Peyman GA, Dietlein J, Fiscella R. Ocular toxicity of experimental intravitreal itraconazole. Int Ophthalmol1991;15:21-4.

87. Shahsavari M, Peyman GA, Niesman MR. Retinal toxicity and in vitro efficacy study of cilofungin (LY121019). Ophthalmic Surg 1990;21:726-8.

88. Dunlap WA, Karaçorlu M, Peyman GA, Nair MG, Rahimy M, Pedroza L. Retinal toxicity of intravitreal injection of faerifungin. Ophthalmic Surg 1994;25:303-6.

89. Serracarbassa PD, Peyman G, Liang C, Calixto Jr N, Nair MG. Toxicity and efficacy of intravitreal spartanamicin B in the treatment of Candida albicans endophthalmitis. Int Ophthalmol 1998;22:53-8.

90. Serracarbassa PD. Estudo experimental da toxicidade retiniana e eficácia da injeção intravítrea de espartanamicina B no tratamento da endoftalmite por Candida albicans [tese]. São Paulo: Faculdade de Medicina da Universidade de São Paulo; 2000.

91. Coats ML, Peyman GA. Intravitreal corticosteroids in the treatment of exogenous fungal endophthalmitis. Retina 1992;12:46-51.

92. Schulman JA, Peyman GA. Intravitreal corticosteroids as an adjunct in treatment of bacterial and fungal endophthalmitis: a review. Retina 1992;12: 336-40.

93. Majji AB, Jalali S, Das T, Gopinathan U. Role of intravitreal dexamethasone in exogenous fungal endophthalmitis. Eye 1999;13:660-5.

\section{Ao enviar um artigo para publicação,}

leia ATENTAMENTE as instruções para autores,

constante no final de cada fascículo. 